\title{
A Novel Expression of Exercise Induced Pulmonary Hypertension in Human Immunodeficiency Virus Patients: A Pilot Study
}

\author{
Rami Doukky ${ }^{1,3, *}$, Won Y. Lee ${ }^{2}$, Mahindhar Ravilla $^{3}$, Omar B. Lateef ${ }^{4}$, Victor Pelaez ${ }^{3}$, \\ Audrey French ${ }^{5}$ and Rajive Tandon ${ }^{4}$
}

${ }^{1}$ Rush University Medical Center, Department of Medicine, Section of Cardiology, 1653 W. Congress Pkwy, Jelke 1015, Chicago, IL 60612, USA

${ }^{2}$ University of Texas Southwestern Medical Center, Department of Medicine, Division of Pulmonary and Critical Care Medicine, 5939 Harry Hines Blvd, Dallas, TX 75390, USA

${ }^{3}$ John H. Stroger, Jr. Hospital of Cook County, Department of Medicine, Division of Adult Cardiology, 1901 W. Harrison Street, Chicago, IL 60612, USA

${ }^{4}$ Rush University Medical Center, Department of Medicine, Division of Pulmonary and Critical Care Medicine, 1750 W. Harrison Street, Jelke 297, Chicago, IL 60612, USA

${ }^{5}$ John H. Stroger, Jr. Hospital of Cook County, Department of Medicine, Division of Infectious Diseases, 1900 W. Polk Street, Chicago, IL 60612, USA

\begin{abstract}
Background: Patients with the human immunodeficiency virus (HIV) are at risk for multiple pulmonary complications including pulmonary hypertension. Exercise induced pulmonary hypertension (EIPH) has been previously described in patients with scleroderma, sickle cell disease and chronic obstructive pulmonary disease, yet has not been associated with the HIV population.

Methods: A prospective case-control study design was implemented. Four HIV patients with unexplained dyspnea and four healthy controls underwent symptom-limited stationary bicycle exercise. Transthoracic Doppler Echocardiography was used to measure tricuspid regurgitation velocity which was used to calculate the right ventricular to right atrial pressure (RV-RA) gradient at rest and at peak exercise using the simplified Bernoulli's equation. Change in RV-RA gradient between rest and peak exercise was calculated and considered to represent change in pulmonary arterial systolic pressure.

Results: The mean age was 41.25 years $( \pm 8.7)$ for patients and 33.5 years $( \pm 6.0)$ for controls. The mean CD4 count of patients was 191.5 cells $/ \mu \mathrm{L}( \pm 136.2)$. Patients had a significantly higher increase in RV-RA gradient as compared to controls $(180.2 \%$ vs. $27.5 \%, \mathrm{p}=0.03)$.

Discussion: This pilot study suggests that it is feasible to use recumbent bicycle and transthoracic Doppler echocardiography for the evaluation of EIPH among HIV patients with dyspnea of unknown etiology. The study is too small to draw any broad conclusion. Further evaluation of this concept with a larger study is warranted.
\end{abstract}

Keywords: Human immunodeficiency virus (HIV), pulmonary hypertension, exercises induced pulmonary hypertension.

\section{BACKGROUND}

Patients with the human immunodeficiency virus (HIV) are at risk for multiple pulmonary complications including infection, malignancy, interstitial lung disease, and pulmonary hypertension $(\mathrm{PH})$. The pathogenesis of HIVassociated $\mathrm{PH}$ is multifactorial and poorly understood. Plexogenic pulmonary arteriopathy is the most common lesion identified, reflective of medial hypertrophy with concentric intimal endothelial proliferation [1-4]. The HIV virus or its related proteins are not present in the vascular endothelium as confirmed using electron microscopy,

*Address correspondence to this author at the Rush University Medical Center, Section of Cardiology, 1653 W. Congress Pkwy, Chicago, IL 60612, Tel: 312-563-2534; Fax: 312-942-6334;

E-mail:rami_doukky@rush.edu immunohistochemistry, polymerase chain reaction, and DNA in situ hybridization [5-7]. HIV-associated $\mathrm{PH}$ has been estimated to occur in $1 / 200(0.5 \%)$ of HIV infected individuals [1] and when associated with worsening World Health Organization (WHO) functional class is an independent predictor of death associated with right heart failure and sudden cardiac death [3, 7].

Exercise-induced pulmonary hypertension (EIPH) has been described in patients with scleroderma [8], sickle cell disease [9], and chronic obstructive pulmonary disease [10]. Some scleroderma patients with EIPH progress to resting $\mathrm{PH}$, which suggests that EIPH may be an early marker of $\mathrm{PH}$ at rest $[9,11]$. PH at rest is well recognized in HIV, yet the phenomenon of EIPH has not been described in this population. 
Unexplained exertional dyspnea is not uncommon among HIV patients. Unfortunately, in some patients no final diagnosis is made despite exhaustive evaluations including searches for pulmonary, cardiovascular, infectious, and malignant etiologies. We believe that unexplained exertional dyspnea in the HIV population may be a clinical presentation of EIPH. By identifying these patients early in their disease, therapeutic strategies to improve immune status with highly active anti-retroviral therapy (HAART) or treatment with pulmonary vasodilators may be initiated and have beneficial effects on quality of life and potentially mortality. We hypothesize that there is a population of HIV patients with exercise-induced $\mathrm{PH}$, similar to other patient groups with secondary causes of $\mathrm{PH}$.

\section{METHODS}

A prospective case-control study design was implemented. Patients with HIV and unexplained dyspnea (cases) were recruited from an academic medical center, a large urban county hospital, and an outpatient HIV center from November 2005 to May 2007. The control subjects were four healthy young volunteers. Inclusion criteria for the cases were HIV patients with unexplained exertional dyspnea and normal chest imaging. Patients were excluded if they had other secondary forms of $\mathrm{PH}$ including thromboembolic disease, other forms of cardiac or valvular dysfunction, autoimmune diseases, severe obstructive sleep apnea, sarcoidosis, sickle cell disease, hyperthyroidism, use of appetite suppressant drugs, or liver cirrhosis. Patients were also excluded if they were pregnant or less than 18 years of age. Patients' functional status was classified according to the New York Heart Association (NYHA) classification. All patients underwent a thorough clinical evaluation of dyspnea by one of the clinical investigators in addition to complete pulmonary function testing. Lung volumes, diffusing capacity, and flow rates were measured using standard American Thoracic Society and European
Respiratory Society guidelines [12]. Patients were excluded if they were identified to have an alternate cause for dyspnea such as obstructive or restrictive lung disease, abnormal diffusing capacity suggestive of thromboembolic disease or interstitial lung disease or markedly abnormal chest imaging. Consequently, eligible patients underwent a complete resting transthoracic echocardiogram. The following echocardiographic abnormalities would result in exclusion from the study: impaired left ventricular systolic or diastolic function, regional wall motion abnormalities, evidence suggestive of elevated left ventricular filling pressure [13], right ventricular dysfunction, more than mild valvular heart disease, any degree of pulmonic valve stenosis, absence of tricuspid regurgitation or baseline elevated systolic pulmonary artery pressures.

Eligible patients and controls exercised on a recumbent bicycle ergometer. The patients were connected to a continuous electrocardiogram (ECG) monitor. The blood pressure and heart rate were measured at rest and during exercise. Symptoms of dyspnea were recorded using the Borg Dyspnea Scale. During exercise symptoms, vital signs, and workload achieved were recorded. Exercise was started at an initial work load of 25 Watts and gradually increased every 3 minutes. Subjects were encouraged to exercise to maximum capacity. The exercise was terminated if the subject complained of symptoms (chest pain, worsening dyspnea, or leg fatigue), ischemic ECG changes, dysrhythmias, hypertension $(>220 / 110 \quad \mathrm{mmHg})$ or hypotension $(>10 \mathrm{mmHg}$ from baseline). Both at rest and at peak-exercise, tricuspid regurgitation jet velocity (TRV) was interrogated using color and continuous-wave Doppler in the following standard views: parasternal right ventricular inflow, parasternal short axis, apical four-chamber, and subcostal (Fig. 1). In all cases, agitated saline was injected to enhance the Doppler signals. The highest TRV was used to calculate the pressure-gradient between the right ventricle and the right atrium (RV-RA) using the simplified Bernoulli
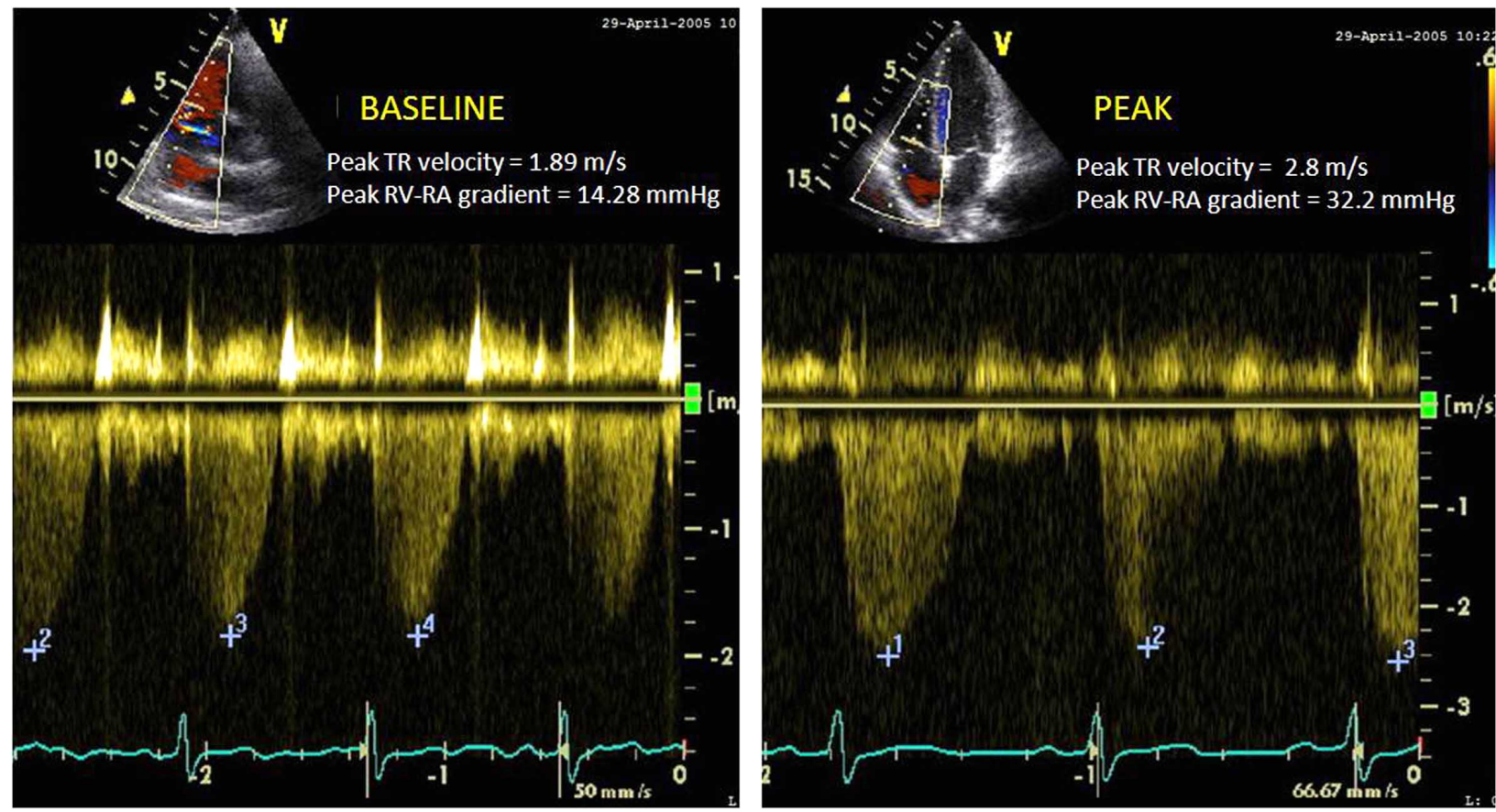

Fig. (1). Peak tricuspid regurgitation jet velocity at rest (A) and at peak exercise (B). 
Table 1. Clinical Characteristics of HIV Patients with Exertional Dyspnea

\begin{tabular}{|c|l|l|l|l|l|l|l|}
\hline & $\begin{array}{l}\text { Age Gender } \\
\text { Race }\end{array}$ & Symptoms & $\begin{array}{l}\text { NYHA } \\
\text { Classification }\end{array}$ & $\begin{array}{l}\text { CD4 count } \\
\left(\mathbf{c e l l s} / \mathbf{m m}^{3}\right)\end{array}$ & $\begin{array}{l}\text { HIV RNA Viral Load } \\
(\mathbf{m m} / \mathbf{C 3})\end{array}$ & $\begin{array}{l}\text { Chest } \\
\text { Imaging }\end{array}$ & $\begin{array}{l}\text { HAART } \\
\text { Therapy }\end{array}$ \\
\hline \hline 1 & $\begin{array}{l}32, \text { Man } \\
\text { African American }\end{array}$ & $\begin{array}{l}\text { Dyspnea } \\
3 \text { months }\end{array}$ & Class III & $<5$ & $>100,000$ & Normal \\
\hline 2 & $\begin{array}{l}37, \text { Man } \\
\text { Hispanic }\end{array}$ & $\begin{array}{l}\text { Dyspnea } \\
12 \text { months }\end{array}$ & Class III & 183 & Undetectable & Normal & Yes \\
\hline 3 & $\begin{array}{l}52, \text { Woman } \\
\text { African American }\end{array}$ & $\begin{array}{l}\text { Dyspnea } \\
6 \text { months }\end{array}$ & Class III & 284 & Undetectable & Normal & Yes \\
\hline 4 & $\begin{array}{l}44, \text { Woman } \\
\text { Hispanic }\end{array}$ & $\begin{array}{l}\text { Dyspnea } \\
2 \text { years }\end{array}$ & Class III & 297 & 2890 & Small Cysts & No \\
\hline 5 & $\begin{array}{l}39, \text { Man } \\
\text { African American }\end{array}$ & $\begin{array}{l}\text { Dyspnea } \\
2 \text { years }\end{array}$ & Class III & 186 & 83 & Normal \\
\hline
\end{tabular}

Table 2. Results

\begin{tabular}{|l|c|c|c|}
\hline & Cases $(\boldsymbol{n}=\mathbf{4})$ & Controls $(\boldsymbol{n}=\mathbf{4})$ & $\boldsymbol{p}$ value \\
\hline \hline Change in RV-RA gradient & $9.4( \pm 6.3) \mathrm{mmHg}$ & $5.3( \pm 1.7) \mathrm{mmHg}$ & 0.25 \\
\hline Percent increase in RV-RA gradient & $180.2 \%( \pm 110.22)$ & $27.5 \%( \pm 8.3)$ & $\mathbf{0 . 0 3}$ \\
\hline Percent change in PASP & $55.3 \%( \pm 24.8)$ & $21.5 \%( \pm 5.7)$ & $\mathbf{0 . 0 4}$ \\
\hline
\end{tabular}

equation [RV-RA gradient $\left.=4 \times \mathrm{TRV}^{2}\right]$ [14] (Fig. 1). The right atrial pressure (RAP) was estimated from inferior vena cava size and collapsibility during inspiration [15]. The pulmonary arterial systolic pressure (PASP) was calculated at rest and peak-exercise from the sum of RV-RA gradient and estimated RAP [PASP $\left.=4 \times \mathrm{TRV}^{2}+\mathrm{RAP}\right][14]$.

Independent samples two-tailed Student's T-test was used to compare percent change in means of RA-RV pressure gradient in response to exercise. Data analysis was performed using SPSS version 18.0 (Chicago, IL). The study was approved by the Rush University Medical Center and John H. Stroger, Jr. Hospital of Cook County Institutional Review Boards.

\section{RESULTS}

Eight patients were initially evaluated for symptoms of exertional dyspnea. All were WHO functional class II or III. Two patients were excluded, one with diffuse lymphadenopathy identified on chest computed tomography which was suggestive of malignancy, and another patient was lost to follow-up. Six patients were further evaluated. One patient met all inclusion criteria including no evidence of primary lung disease, no coronary ischemia, and normal resting echocardiogram; however was lost to follow-up and never underwent an exercise study. Patient 5 (Table 1) had normal chest imaging, normal pulmonary function studies, no evidence of coronary ischemia, an unremarkable cardiopulmonary exercise test, and a normal resting echocardiogram. However peak-exercise TRV could not be identified (despite contrast enhancement) and therefore his data is not included in the analysis. The remaining four patients are included in final data analysis.

The four patients ( 2 women and 2 men) who were included in the analysis had a mean age of 41.25 years $( \pm 8.7)$ and a mean CD4 count of 191.5 cells $/ \mu \mathrm{L}( \pm 136.2)$ (Table $\mathbf{1})$. The mean age of controls was 33.5 years $( \pm 6.0)$. Patients exercised on a recumbent bicycle to a mean Borg Dyspnea score of 3.8; which correlates with moderate to severe impairment. Among HIV patients, the mean resting RV-RA gradient was $6.4 \mathrm{mmHg}( \pm 5.4)$ and the mean peak-exercise $\mathrm{RV}$-RA gradient was $15.8 \mathrm{mmHg}( \pm 11.2)$. Among controls, the mean resting RV-RA gradient was $20.0( \pm 7.2) \mathrm{mmHg}$ and the mean RV-RA gradient at peak-exercise was 25.3 $( \pm 8.5) \mathrm{mmHg}$. In all cases and controls the TRV, the RV-RA gradient and the PASP increased with exercise. The absolute increase in mean RV-RA gradient among patients was 9.4 $( \pm 6.3) \mathrm{mmHg}$ compared to $5.3( \pm 1.6) \mathrm{mmHg}$ among controls; a statistically insignificant difference $(\mathrm{p}=0.25)$. However, the percentage change in RV-RA gradient relative to baseline among cases was $+180.2 \%( \pm 110.2)$, compared to $+27.5 \%( \pm 8.3)$ among controls; a statistically significant difference $(\mathrm{p}=0.03)$ (Table 2). Similarly, the percentage increase in the calculated PASP relative to baseline among cases was $55.3 \%( \pm 24.8)$, compared to $21.5 \%( \pm 5.7)$ among controls; a statistically significant difference $(\mathrm{p}=0.04)$ (Table 2).

\section{DISCUSSION}

We detail the first description of HIV patients with exercise-induced increase in Doppler-measured pulmonary 
pressure in excess to that observed in healthy volunteers. This phenomenon has previously been reported in patients with scleroderma, sickle cell disease, and COPD, but to our knowledge, has not yet been described in the HIV population. In our patients, alternative causes of dyspnea were thoroughly evaluated including opportunistic infections, underlying pulmonary or cardiovascular diseases, or thromboembolism. Our research suggests that exercise echocardiography searching for EIPH should be considered in the clinical evaluation of unexplained dyspnea in the HIV patient.

Pulmonary hypertension is increasingly recognized as a complication of HIV leading to worsening mortality. Patients with HIV-associated $\mathrm{PH}$ have a median survival of 1.3 years which is worse than the 2.6 year survival reported in primary pulmonary hypertension patients [16]. Furthermore, the median time interval between diagnosis of HIV related $\mathrm{PH}$ and death is only 6 months [3]. Therefore, identification of these patients during early stages of the disease may lead to initiation of therapy which has the potential to modify symptoms and possibly mortality.

Measurement of tricuspid regurgitation jet velocity by echocardiography is generally reliable in detecting both resting and exercise $\mathrm{PH}[10,17,18]$. The advantage of echocardiography is its noninvasive nature, reproducibility and favorable correlation to invasive measurement techniques $[19,20]$. Furthermore, echocardiography is useful in excluding other causes of elevated right-sided pressures such as valvular or congenital heart disease [21]. However, when evaluating a patient with exertional dyspnea, the resting pulmonary pressure does not reflect exercise hemodynamics. During exercise, there normally is an increase in stroke volume, relatively small increases in pulmonary artery pressures, yet an overall decrease in pulmonary vascular resistance [19]. Nonetheless, scleroderma patients with EIPH typically show increases in pulmonary artery systolic pressures, reflective of increased vascular resistance during exercise [8]. Doppler echocardiography, therefore, is reliable in distinguishing pathologic from physiologic responses to exercise and has been utilized to identify EIPH in both the recumbent and supine position $[8,17,18]$. In our study, we applied the Bernoulli equation on the measured tricuspid regurgitant velocity to calculate the RV-RA gradient at rest and peak-exercise. Assuming that the right atrial pressure is constant, any change in the RV-RA gradient between the resting state and peak-exercise reflects equal change in the pulmonary arterial systolic pressure.

We also found that the patient with the highest increase in RV-RA gradient was the patient with the lowest CD4+ Tlymphocyte count. The other 3 patients had average CD4+ T-lymphocyte counts greater than 200 cells $/ \mathrm{mm}^{3}$. The role that the degree of immunodeficiency and viral load have on the development of HIV-associated PH is conflicting [22]. In one retrospective study, initiation of HAART therapy alone resulted in significant regression of RV-RA gradient suggesting that HIV may trigger mechanisms leading to increases in pulmonary vascular resistance [23, 24]. Nunes ${ }^{7}$ showed that patients receiving combination antiretroviral therapy and a CD4 count greater than 212 cells $/ \mathrm{mm}^{3}$ had an improved mortality. However, other investigators note the lack of correlation between the development of PH in HIV individuals and their level of immunodeficiency or CD4+ Tlymphocyte counts $[16,25]$. HIV related $\mathrm{PH}$ can occur early and in late stages of HIV infection and does not always seem related to degree of immunodeficiency [26]. Therefore in any HIV patient with unexplained dyspnea a clinical investigation for $\mathrm{PH}$ is warranted, regardless of the immune status.

Other therapeutic strategies for HIV related $\mathrm{PH}$ may include vasodilator treatment such as prostacyclin analogues, endothelin antagonists or phosphodiesterase inhibitors. These agents are typically reserved for more severe WHO Class III or IV patients. The use of intravenous epoprostenol in patients with $\mathrm{HIV}$-associated $\mathrm{PH}$ has shown favorable improvements in hemodynamic parameters; decreases in pulmonary artery pressures and pulmonary vascular resistance, increase in cardiac index, and improved clinical and exercise status [7, 16, 27]. The risks of chronic intravenous epoprostenol therapy requiring central line placement and the potential for catheter related blood stream infections may preclude use of continuous infusion in these patients. Other therapies include targeting endothelin-1, a potent vasoconstrictor and important component of the pathogenesis of HIV-associated PH. This highlights the benefits of endothelin antagonists such as bosentan and ambrisentan [28, 29]. Finally, the ease with which oral phosphodiesterase inhibitors can be administered may also lead to promising treatment strategies [30-32]. As far as HIV-associated PH or EIPH, there have been no studies evaluating the use of pulmonary artery vasodilators, yet we can only hypothesize that clinical treatment may improve WHO functional class or 6-minute walk distance.

\section{Limitations}

There are several limitations to our study. First, the number of patients and controls studied is small. It was challenging to identify subjects with HIV and unexplained dyspnea who met all the enrollment criteria. Secondly our investigation lacks confirmation by right-heart catheterization, which remains the best diagnostic tool to assess pulmonary hemodynamics. However, it is difficult to enroll patients in an investigation that involves such invasive testing. Therefore, we felt that measurement of TRV by Doppler-echocardiography is noninvasive and reliable and has been a useful research tool in a number of previous studies. Thirdly, acquiring a "perfect" tricuspid regurgitation Doppler signal with a clearly identifiable peak-velocity while the patient is actively engaged in bicycle exercise was particularly challenging. This was most problematic in three of the four patients enrolled. It seems that this has not been a problem for the control subjects enrolled later in the study, as our echocardiography technologist became more comfortable with acquisition. When the peak TRV was not clearly identifiable we recorded the highest discernable velocity which may not reflect peak TRV in those subjects. This problem questions, to some extent, the validity and reproducibility of our findings and stresses the importance of 
standardizing the mode of exercise and patient position during Doppler-echocardiography acquisition in the detection of EIPH. Finally, long term follow-up was not established and therefore progression to resting $\mathrm{PH}$ is purely hypothetical. Larger studies with confirmation by right-heart catheterization and long-term follow-up may best clarify the pathophysiology and clinical characteristics of EIPH in the HIV population.

\section{CONCLUSION}

We describe the first report of four HIV patients with exercise induced dyspnea without evidence of $\mathrm{PH}$ at rest, yet with manifestations of exercise-induced increase in pulmonary systolic pressure. EIPH may be an early marker for HIV-associated PH or purely exist as an exercise induced phenomenon. Our preliminary data is limited by a small sample size, yet may lead to larger investigations of this novel disease process. If identified, both cause and treatment need to be further investigated as there still remains clinical uncertainty regarding the prevalence of HIV-associated EIPH and the progression of the disease. By establishing an early and accurate diagnosis, HIV patients can be targeted for careful follow-up and potential treatment to lower pulmonary artery pressures, although further studies are warranted to address this issue. Finally, since HLA-DR6 and DR52 have been associated in the pathogenesis of HIVassociated PH [33], genetic analysis using single nucleotide polymorphisms may identify candidate genes involved in the development of EIPH.

\section{FUNDING}

Rush University Medical Center and John H. Stroger Hospital of Cook County Collaborative Research Grant

\section{CONFLICT OF INTEREST}

Declared none.

\section{ACKNOWLEDGEMENT}

Declared none.

\section{REFERENCES}

[1] Speich R, Jenni R, Opravil M, Pfab M, Russi EW. Primary pulmonary hypertension in HIV infection. Chest 1991; 100: 1268-71.

[2] Mesa RA, Edell ES, Dunn WF, Edwards WD. Human immunodeficiency virus infection and pulmonary hypertension: two new cases and a review of 86 reported cases. Mayo Clin Proc 1998; 73: 37-45.

[3] Mehta NJ, Khan IA, Mehta RN, Sepkowitz DA. HIV-Related pulmonary hypertension: analytic review of 131 cases. Chest 2000; 118: 1133-41.

[4] Polos PG, Wolfe D, Harley RA, Strange C, Sahn SA. Pulmonary hypertension and human immunodeficiency virus infection. Two reports and a review of the literature. Chest 1992; 101: 474-8.

[5] Mette SA, Palevsky HI, Pietra GG, et al. Primary pulmonary hypertension in association with human immunodeficiency virus infection. A possible viral etiology for some forms of hypertensive pulmonary arteriopathy. Am Rev Respir Dis 1992; 145: 1196-200.

[6] Humbert M, Monti G, Fartoukh M, et al. Platelet-derived growth factor expression in primary pulmonary hypertension: comparison of HIV seropositive and HIV seronegative patients. Eur Respir J 1998; $11: 554-9$.

[7] Nunes H, Humbert M, Sitbon O, et al. Prognostic factors for survival in human immunodeficiency virus-associated pulmonary arterial hypertension. Am J Respir Crit Care Med 2003; 167: 1433-9.

[8] Alkotob ML, Soltani P, Sheatt MA, et al. Reduced exercise capacity and stress-induced pulmonary hypertension in patients with scleroderma. Chest 2006; 130: 176-81.

[9] Anthi A, Machado RF, Jison ML, et al. Hemodynamic and functional assessment of patients with sickle cell disease and pulmonary hypertension. Am J Respir Crit Care Med 2007; 175: 1272-9.

[10] Himelman RB, Stulbarg M, Kircher B, et al. Noninvasive evaluation of pulmonary artery pressure during exercise by salineenhanced Doppler echocardiography in chronic pulmonary disease. Circulation 1989; 79: 863-71.

[11] Callejas JL, Moreno E, Martin P, Lopez-Perez L, Ortego N. Stressinduced pulmonary systolic hypertension in patients with scleroderma. Chest 2007; 131: 1267; author reply 1267.

[12] Miller MR, Crapo R, Hankinson J, et al. General considerations for lung function testing. Eur Respir J 2005; 26: 153-61.

[13] Nagueh SF, Appleton CP, Gillebert TC, et al. Recommendations for the evaluation of left ventricular diastolic function by echocardiography. J Am Soc Echocardiogr 2009; 22: 107-33.

[14] Oh JK. The Echo Manual. Third ed: USA: Lippincott Williams \& Wilkins 2007.

[15] Stein JH, Neumann A, Marcus RH. Comparison of estimates of right atrial pressure by physical examination and echocardiography in patients with congestive heart failure and reasons for discrepancies. Am J Cardiol 1997; 80: 1615-8.

[16] Farber HW. HIV-associated pulmonary hypertension. AIDS Clin Care 2001; 13: 53-9.

[17] Bossone E, Avelar E, Bach DS, Gillespie B, Rubenfire M, Armstrong WF. Diagnostic value of resting tricuspid regurgitation velocity and right ventricular ejection flow parameters for the detection of exercise induced pulmonary arterial hypertension. Int $\mathbf{J}$ Card Imaging 2000; 16: 429-36.

[18] Bossone E, Chessa M, Butera G, et al. Echocardiographic assessment of overt or latent unexplained pulmonary hypertension. Can J Cardiol 2003; 19: 544-8.

[19] Braunwald's. Heart Disease: A Textbook of Cardiovascular Medicine. Eighth ed. Philadelphia: Elseiver 2008.

[20] Naeije R, Torbicki A. More on the noninvasive diagnosis of pulmonary hypertension: Doppler echocardiography revisited. Eur Respir J 1995; 8: 1445-9.

[21] Bossone E, Bodini BD, Mazza A, Allegra L. Pulmonary arterial hypertension: the key role of echocardiography. Chest 2005; 127: 1836-43.

[22] Kanmogne GD. Noninfectious pulmonary complications of HIV/AIDS. Curr Opin Pulm Med 2005; 11: 208-12.

[23] Speich R, Jenni R, Opravil M, Jaccard R. Regression of HIVassociated pulmonary arterial hypertension and long-term survival during antiretroviral therapy. Swiss Med Wkly 2001; 131: 663-5.

[24] Zuber JP, Calmy A, Evison JM, et al. Pulmonary arterial hypertension related to HIV infection: improved hemodynamics and survival associated with antiretroviral therapy. Clin Infect Dis 2004; 38: 1178-85.

[25] Limsukon A, Saeed AI, Ramasamy V, Nalamati J, Dhuper S. HIV-related pulmonary hypertension. Mt Sinai J Med 2006; 73 1037-44.

[26] Petitpretz P, Brenot F, Azarian R, et al. Pulmonary hypertension in patients with human immunodeficiency virus infection. Comparison with primary pulmonary hypertension. Circulation 1994; 89: 2722-7.

[27] Aguilar RV, Farber HW. Epoprostenol (prostacyclin) therapy in HIV-associated pulmonary hypertension. Am J Respir Crit Care Med 2000; 162: 1846-50.

[28] Sitbon O, Gressin V, Speich R, et al. Bosentan for the treatment of human immunodeficiency virus-associated pulmonary arterial hypertension. Am J Respir Crit Care Med 2004; 170: 1212-7.

[29] Barbaro G, Lucchini A, Pellicelli AM, Grisorio B, Giancaspro G, Barbarini G. Highly active antiretroviral therapy compared with 
HAART and bosentan in combination in patients with HIVassociated pulmonary hypertension. Heart 2006; 92: 1164-6.

[30] Schumacher YO, Zdebik A, Huonker M, Kreisel W. Sildenafil in HIV-related pulmonary hypertension. AIDS 2001; 15: 1747-8.

[31] Carlsen J, Kjeldsen K, Gerstoft J. Sildenafil as a successful treatment of otherwise fatal HIV-related pulmonary hypertension. AIDS 2002; 16: 1568-9.
[32] Alp S, Schlottmann R, Bauer TT, Schmidt WE, Bastian A. Longtime survival with HIV-related pulmonary arterial hypertension: a case report. AIDS 2003; 17: 1714-5.

[33] Barbaro G. Cardiovascular manifestations of HIV infection. Circulation 2002; 106: 1420-5.

Received: November 04, 2011

Revised: February 21, 2012

Accepted: February 27, 2012

(C) Doukky et al.; Licensee Bentham Open.

This is an open access article licensed under the terms of the Creative Commons Attribution Non-Commercial License (http://creativecommons.org/licenses/ by-nc/3.0/) which permits unrestricted, non-commercial use, distribution and reproduction in any medium, provided the work is properly cited. 